\title{
REVIEW ON MPPT TECHNIQUES USED IN PV SYSTEM
}

\author{
Neha Dahate \\ PG Student, Department of Electrical Engineering, Government College of Engineering \\ Aurangabad, Maharashtra, India

\section{Dr. N.R. Bhasme} \\ Associate Professor, Department of Electrical Engineering, Government College of \\ Engineering Aurangabad, Maharashtra, India
}

\begin{abstract}
Production of fossil fuel energy is decreasing but the demand for electrical power is rapidly increasing day by day. Solar energy is used because it is clean energy, and also is abundant in nature and has a lot of scope for future development. Maximum power point tracking (MPPT) is an algorithm method used in power electronic circuits to extract maximum power from the solar Photovoltaic (PV) Systems. This paper summarizes the development of a photovoltaic solar system based techniques like Incremental conductance, Fractional open-circuit voltage, Perturb and observe, Fractional short-circuit current and Fuzzy logic that improves accuracy, stability, and efficiency of $P V$ systems.
\end{abstract}

Keywords: MPPT Techniques, Solar energy, Renewable, Energy Sources, Photovoltaic

Cite this Article: Neha Dahate and Dr. N.R. Bhasme, Review on Mppt Techniques Used in Pv System, International Journal of Electrical Engineering \& Technology, 10(4), 2019, pp. 22-30.

http://iaeme.com/Home/issue/IJEET?Volume=10\&Issue=4

\section{INTRODUCTION}

It may Natural resources like geothermal heat, wind, sunlight, rains, and tides are called renewable energy sources. In upcoming years solar energy generation has become an important part of power generation related to electrical use. The most widely used technology is solar photovoltaic (SPV) technology which is sustainable renewable energy sources. However, the generation of electricity by a photovoltaic panel is an unreliable energy source because it depends on various factors such as solar radiation, temperature, and distributed characteristics of sun rays, dust, and shadow and so on. In 2020 India would produce $20 \mathrm{GW}$ of solar power and we realized that India is generating less than half of its potential.

In a solar panel system, the main disadvantage is that its efficiency is very low and the cost of each Kilo-Watt-hour (KWh) is very high. The solar panel is capable of converting 30 to $40 \%$ 
of total energy falling on its panel into usable electrical energy. In a solar power system for modification of efficiency charge controllers and other devices are used, which are inefficient and costly. In this paper, we will discuss an MPPT algorithm which is an accurate charge controller. For tracking the maximum power from the solar photovoltaic system MPPT algorithm can be used. Maximum power can be tracked from various renewable resources. For the collective effectiveness of the solar panel system, the Maximum Power Point Tracking (MPPT) algorithm is required. There are various types of MPPT algorithms such as Perturb and Observe ( $\mathrm{P}$ and $\mathrm{O}$ ), Incremental Conductance ( $\mathrm{InC})$, Fractional Short Circuit Current, Fractional Short-Circuit Current, Fractional Open-Circuit Voltage, Fuzzy Controller, etc. After comparing all the above-mentioned techniques, Incremental Conductance and Perturb and Observe are generally used because of their ease in execution. The variable factors which are used in the algorithm are efficiency, complication, convergence speed, sensors \& cost. This paper summarizes five MPPT methods such as $\mathrm{P}$ and $\mathrm{O}$, InC, fractional open-circuit voltage, fractional short circuit current and the fuzzy logic method.

Normally, Efficiency of solar photovoltaic cell which is used commercially is in the range of 6 to $16 \%$ in which technology plays a vital role. For maximum conversion efficiency, electrical and mechanical mechanism are used. To maintain the solar PV panel position perpendicular to sun rays, so that they can track maximum power, sun tracker can be used. The basic diagram of the MPPT system used in PV modules is shown in Fig. 1[1].

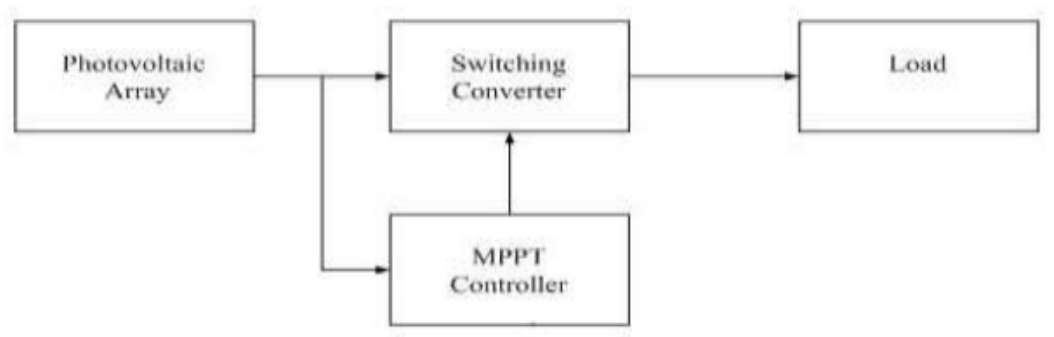

Figure 1 MPPT controlled PV system block diagram [1].

\section{PHOTOVOLTATIC GENERATOR DESCRIPTION}

Photoelectric cell or photovoltaic panel is a semiconductor device that transforms sunlight rays to electrical energy by the PV outcome. The circuit diagram of the electrical cell is as shown in Fig. 2. The resistances are connected in parallel and series to fulfill requirements.

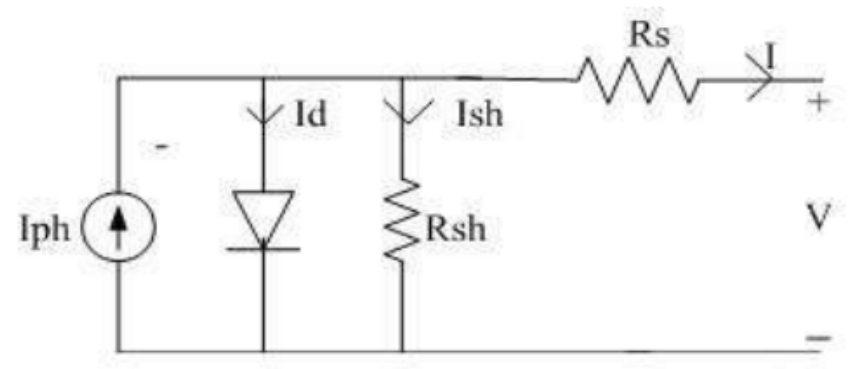

Figure 2 Circuit diagram of equivalent electrical cell

$$
\begin{aligned}
& \text { [2] Iph }=I d+I s h+I \\
& I d=I\left(e^{\frac{q(v+I R s)}{K T A}}-1\right)
\end{aligned}
$$


$I=I p h-I o\left(e^{\frac{q(v+I R s)}{K T A}}-1\right)-\frac{V+I R s}{R s h}$

Where,

$\mathrm{V} \quad=$ Load voltage

I $\quad=$ Cell current (Ampere)

$\mathrm{I}_{\mathrm{D}} \quad=$ Current of diode (Ampere)

Rs $=$ Internal series resistance $(\mathrm{Ohm})$

Rsh = Shunt resistance $(\mathrm{Ohm})$

$\mathrm{I}_{\mathrm{o}} \quad=$ Diode inverse saturation current (Ampere)

$\mathrm{T}=$ Temperature (Kelvin)

$\mathrm{K}=$ Boltzmann constant $\left(1.38 \times 10^{-23} \mathrm{~J} / \mathrm{K}\right)$

$\mathrm{N} \quad=$ Idealist factor $(\approx 1.92)$

$\mathrm{Q} \quad=$ Electrical charge $\left(\mathrm{q}=1.6 \times 10^{-19} \mathrm{C}\right)[3]$

The power voltage $(\mathrm{P}-\mathrm{V})$ characteristics are shown in the photovoltaic module for various standards of solar sun irradiation and the temperature graph is shown in Fig. 3. and in Fig. 4[4]. Thus, it is seen that the characteristics of output are non-linear and directly affected by temperature, radiation of solar, and load condition. For maximization of the output power from a photovoltaic cell, it should be operated at the specified current and voltage values at a unique point and also that in specified load resistance. Therefore, distinct power converter circuit MPPT is used. In this design, a dc-dc boost type converter is used to maximize output and efficiency.

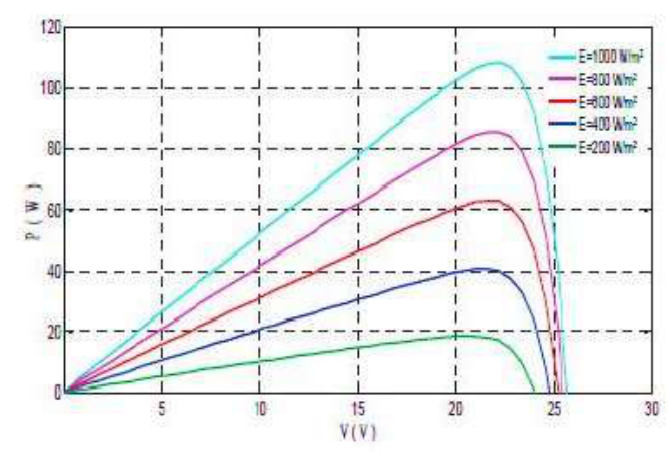

Figure 3 Power characteristics for different irradiation level of PV [4]

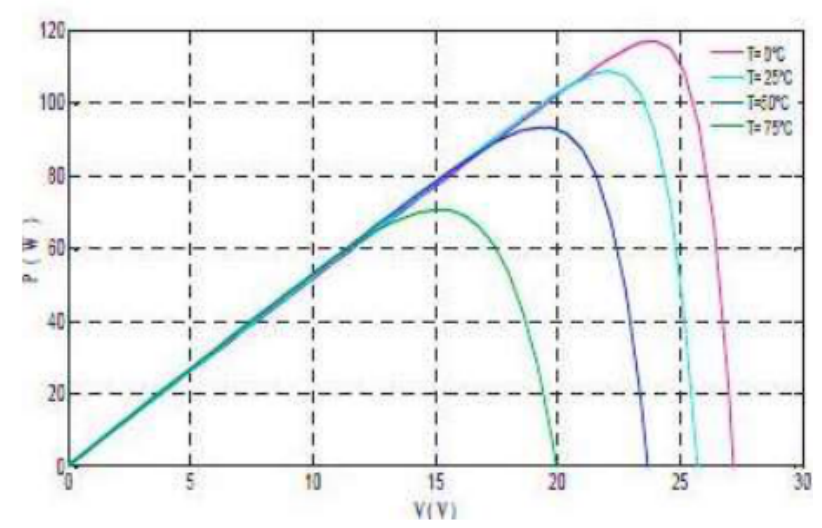

Figure 4 Photovoltaic generator for various temperature[4]. 


\section{DC TO DC BOOST CONVERTER}

This type of boost converter is used to convert DC to DC with rising voltage across output which has a decreasing source voltage; it also termed as step-up DC-DC converter. It will increase the voltage of input from the panel. As the voltage of output increases the output current is decreased $\&$ its converter power is reserved $(\mathrm{P}=\mathrm{VI})$.

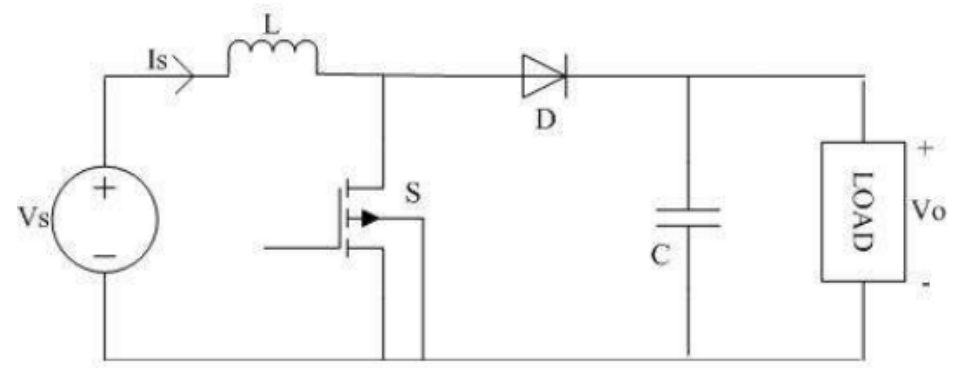

Figure 5 Equivalent Circuit of DC to DC converter[5]

Fig.5. Illustrate the MPPT boost converter circuit which has switch S (MOSFET), output diode $\mathrm{D}, \mathrm{L}$ inductor for boosting, $\mathrm{C}$ capacitor filter and resistive load. While the semiconductor device is closed, the current start flowing and stores the energy thus current through inductor will increase. Off-state means the switch is open energy stored will starts discharging in opposite polarity and starts charging the capacitor and the current will start flow through the load. The transfer function of the boost type converter is obtained by considering its steady state operation. The DC voltage transfer function is [4]:

$$
M(\delta)=\frac{V o}{V i}=\frac{-\delta}{1-\delta}
$$

\section{TYPES OF MPPT TECHNICES}

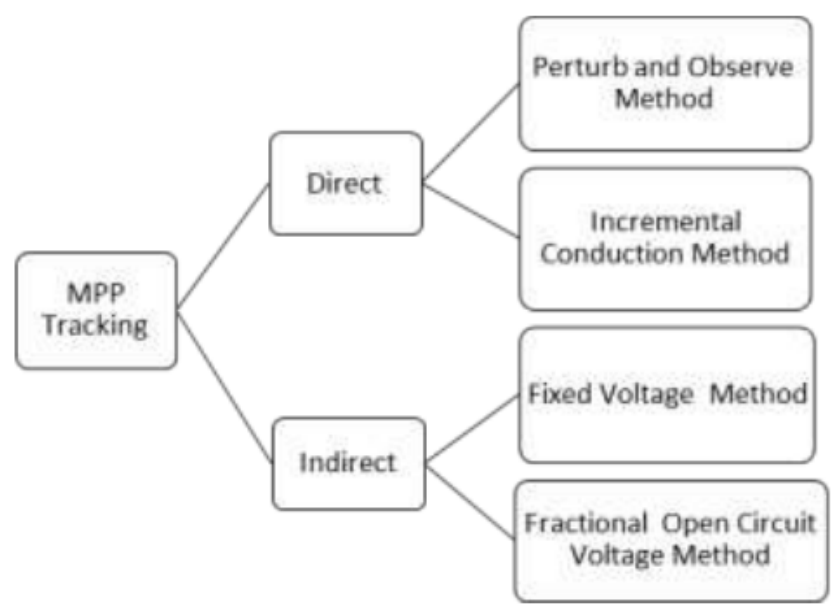

Figure 6 Block diagram of types of MPPT techniques

In a system, the maximum power is extracted from the electronic type system that operates photovoltaic modules. Between the PV system and load, MPPT is installed. In maximum power transfer coupling, the load is required for providing a lesser voltage at the higher current or higher voltage at a lesser current. In Fig.6.shows the block diagram of MPP tracking that has two methods that are direct and indirect. For improving the efficiency of sun photovoltaic, tracking of maximum power point is recycled in the system. Many techniques had introduced in the MPPT system however in this paper $\mathrm{P} \& \mathrm{O}, \mathrm{InC}$, fixed voltage and fractional open circuit 
voltage method are discussed. Near about $40-50 \%$ of the solar radiation to electrical power transformation done through the PV panel.

\subsection{Perturb and observe method}

$\mathrm{P}$ and $\mathrm{O}$ system is normally used technique and also implemented where hardware is used. This technique is different from other techniques, in terms of cost, convergence speed, sensors castoff, complexity, range of usefulness, tracing during irradiation and/ or temperature difference. The voltage sensor is used for intelligence in solar array voltage. The mathematical condition for perturbing and observe is $\mathrm{dp} / \mathrm{dv}=0$, where $\mathrm{P}$ is power and $\mathrm{V}$ is the voltage at the output of the module [1]. The price required is less and it is simple to install. The time required for the algorithm is low but while reaching near to MPP it does not stop and a disturbance is increasing in both directions. As this P\&O technique reached to MPP then for limiting the disturbance we have to do an appropriate error setting. In this algorithm, perturbation is introduced and causes power loss. Due to perturbation, power is increased and perturbation is continued in the equal direction. When it is reached to the maximum level of the MPP power is zero and after that, the reversal of perturbation is shown in Fig. 7. At the steady-state, the algorithm oscillates. For the less power variation, the perturbation should keep small. For reaching a particular voltage level a PI controller is used. While changes in the atmospheric conditions it flops to track the power because of perturbation, then also this technique is in demand.

The flowchart is shown in Fig. 8. Oscillates around the ultimate point when it reached to steady-state. The perturbation is very small for low power regulation. A PI controller then acts moving the operating point of the solar module to that particular voltage level. To track the power that keeps changing under rapid varying weather conditions. Due to irradiance, there is a loss in power generation. But still, this algorithm is simple and very popular $[2,3]$.

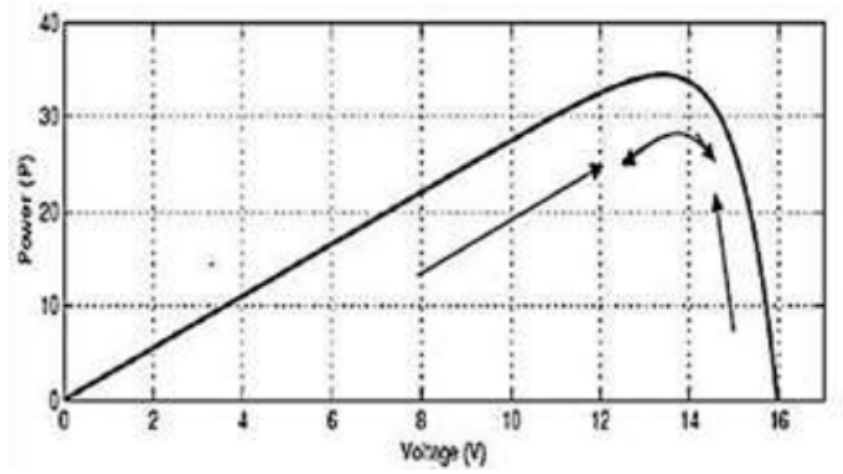

Figure 7 Power Vs Voltage graph for perturb and observe [3]

During the stable condition, there will be an oscillation of algorithm at the peak power point, thus for maintaining the variation in the power, the perturbation is remained small in size. Transferring the point of operation towards the particular voltage level of the module in a PIcontroller there will be power loss. Hence there are flops to track maximum power in rapid atmospheric changes performance. 


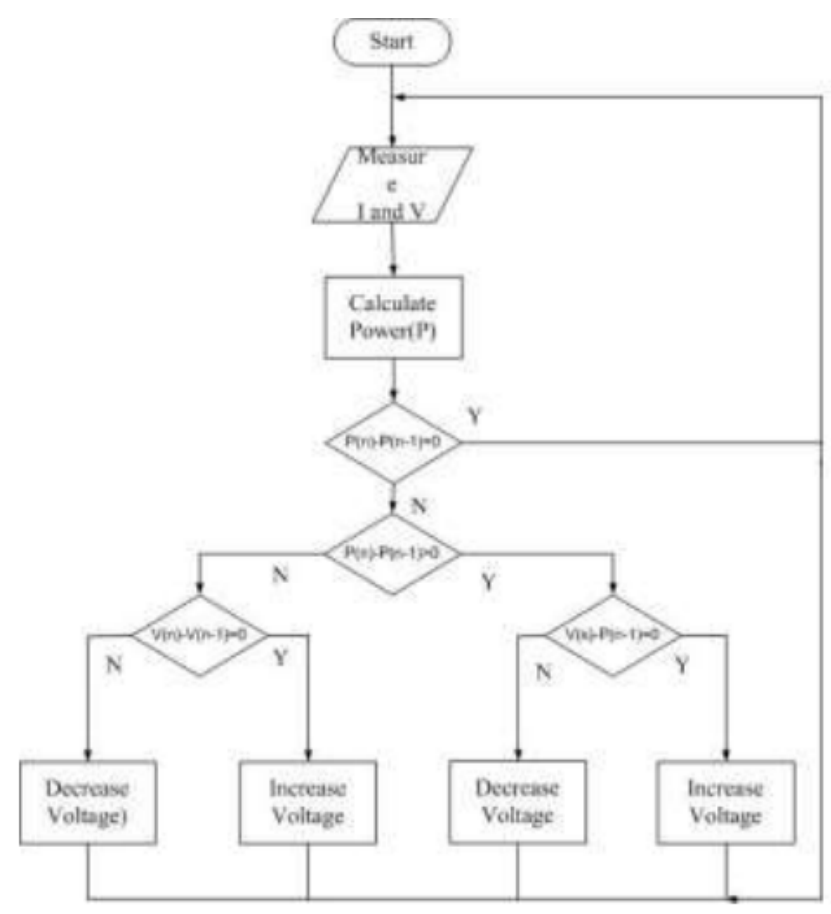

Figure 8 Perturb and observe algorithm flowchart [7]

\subsection{Incremental and Conductance}

In addition to perturb \& observe, the incremental conductance technique is other type of common method of tracking maximum power point. This algorithm was introduced to detect the fault of the $\mathrm{P} \& \mathrm{O}$ algorithm as discussed. The main disadvantage related to the $\mathrm{P} \& \mathrm{O}$ technique that it does not have the ability to compare the array terminal voltage with operating voltage maximum power point. The advantage of the InC algorithm over the conventional method is that it has better efficiency, easy to execute as well as provides greater tracking speed [7].

As rapidly varying the atmospheric condition the tracking of maximum power is eliminated by using the Incremental and conductance method. When incremental conductance MPPT has reached maximum power point then it will stop in perturbing the operating point. It is used to sense voltage \& current with the help of the sensor for sensing the output of the solar panel. Simultaneously sensing both current and voltage this will help to eliminate the errors which occur due to change in irradiance. The slope is based on PV panel power versus voltage curve is

$\frac{\Delta I}{\Delta V}+\frac{I}{V}=0$

$\frac{\Delta I}{\Delta V}+\frac{I}{V}>0$ Left MPP

$\frac{\Delta I}{\Delta V}+\frac{I}{V}<0$ Right MPP

Where, $(\mathrm{I} / \mathrm{V})$ is Instantaneous conductance \& incremental conductance is $(\Delta \mathrm{I} / \Delta \mathrm{V})$.

Only disadvantage of Incremental Conductance over P\&O algorithm is that implementation of cost and complexity increases. 


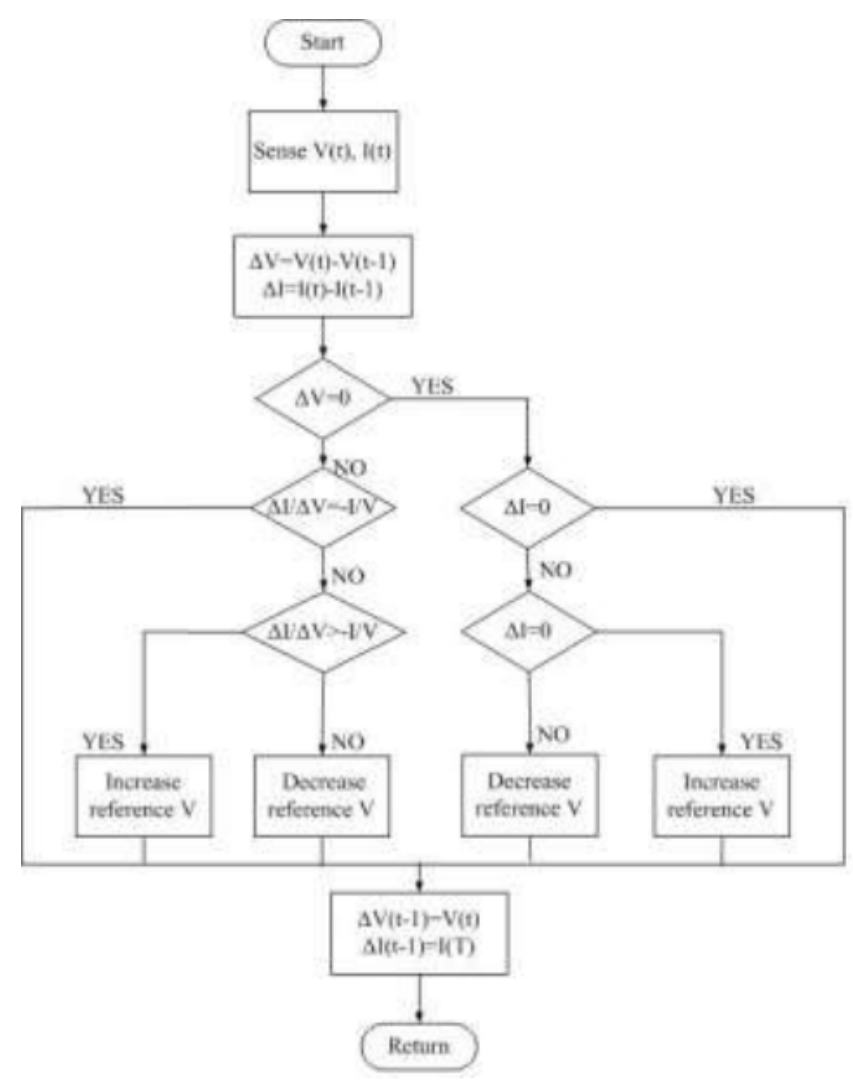

Figure 9 Incremental Conductance algorithm flow chart [7]

\subsection{Fractional open circuit voltage method}

Under the changing condition of irradiance as well as the temperature level of the PV system, it develops the fractional Voc method. Relationship between VMPP and Voc of the solar panel is nearly linear.

$\mathrm{V}_{\mathrm{MPP}}=\mathrm{K}_{1} \mathrm{~V}_{\mathrm{oc}}$

Where, $\mathrm{K} 1$ is proportionality constant

For different PV array, there are different temperatures and different irradiance. The value of $\mathrm{K} 1$ factor is between 0.71 to 0.78 . As the value of $\mathrm{K} 1$ is determined, VMPP can be calculated with Voc decreasing the power converter. One of the disadvantages is there is loss of power.

\subsection{Fractional short circuit current}

As an atmospheric condition changes Impp is nearly linear to the Isc of PV array which results in fractional Isc.

$$
\mathrm{I}_{\mathrm{MPP}}=\mathrm{K}_{2} \mathrm{I}_{\mathrm{sc}}
$$

$\mathrm{K} 2$ is proportional to constant, where $\mathrm{K} 2$ is between the values of 0.78 to 0.92 . During operation Isc is in trouble, therefore, one switch is additional toward the power converter. Because of that Isc be able to measure via the current sensor of the PV array.

\subsection{Fuzzy logic control}

The fuzzy logic controller is the most dynamic and useful research area and generally useful for the control of various physical methods. The human experience is used for the design of fuzzy logic than a mathematical model for the controlling system. FLC (fuzzy logic control) is used where the system is a very complex or highly nonlinear character. It is also used to 
determine the duty cycle of the step-down converter. The input over FLC is error value and changes in error. The problem in mathematical models or limitations in control methods is one of the useful control schemes in FLC. Fuzzy logic is a rule-based decision process and also developing various control rules. It is more robust than conventional controllers. The most important part of FLC is fuzzification, fuzzy inference, defuzzification as illustrated in figure 8.

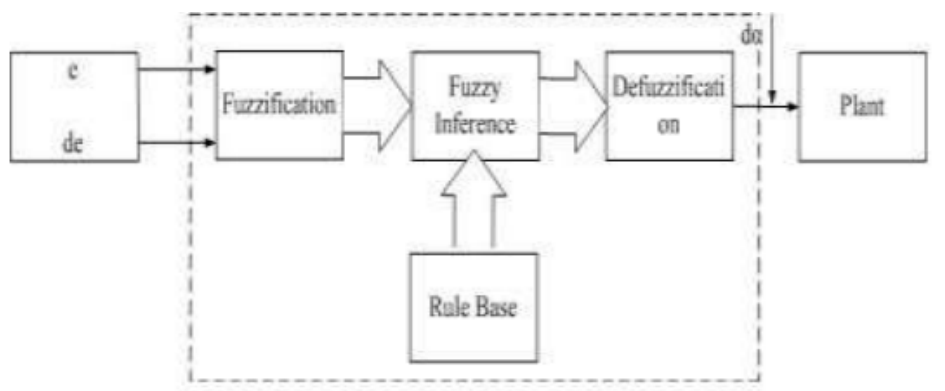

Figure 10 Fuzzy logic controller block diagram [10]

For getting the value of current and voltage generated by photovoltaic is used in error besides change in error values. In below equation the values are defined.

$$
E(k)=\frac{p(k)-p(k-1)}{v(k)-v(k-1)}
$$

$\Delta E(k)=E(k)-E(k-1)$

$\mathrm{E}(\mathrm{k})$ as error value at $\mathrm{k}$ sampling time

$\mathrm{E}(\mathrm{k}-1)$ as error value at $(\mathrm{k}-1)$ sampling time

$\Delta \mathrm{E}(\mathrm{k})$ changes in error also values in power and voltage

\section{COMPARISION OF MPPT TECHNIQUES}

\begin{tabular}{|c|c|c|c|c|}
\hline $\begin{array}{c}\text { MPPT } \\
\text { Techniques }\end{array}$ & $\begin{array}{c}\text { Implementation } \\
\text { complexity }\end{array}$ & $\begin{array}{c}\text { Convergence } \\
\text { speed }\end{array}$ & $\begin{array}{c}\text { Periodic } \\
\text { Tuning }\end{array}$ & $\begin{array}{c}\text { Sensed } \\
\text { parameter }\end{array}$ \\
\hline P\&O & Low & Fluctuates & No & Voltage \\
\hline InC & Moderate & Fluctuates & No & $\begin{array}{c}\text { Voltage, } \\
\text { Current }\end{array}$ \\
\hline Fraction $\mathrm{V}_{\text {oc }}$ & Low & Moderate & Yes & Voltage \\
\hline Fraction Isc & Moderate & Moderate & Yes & Current \\
\hline $\begin{array}{c}\text { Fuzzy logic } \\
\text { controller }\end{array}$ & High & Fast & Yes & Varies \\
\hline
\end{tabular}

\section{CONCLUSION}

Solar energy is present in abundance in nature and thus can be used to solve many of the environmental problems. In this review paper, various types of MPPT algorithm techniques are explained. Each MPPT technique is different from one another having its own benefits and drawbacks. The method based on Perturb \& Observe technique is most widely employed in commercial production. This $\mathrm{P} \& \mathrm{O}$ technique can be implemented with low-price. It can be 
easily used along hardware, also provides high strength and good MPPT efficiency. For any pre-defined application, there is always a need for selecting a proper MPPT algorithm. This paper can be helpful to the researchers so as to make the decision efficiently.

\section{REFERENCES}

[1] Abhishek Kumar Gupta, Ravi Saxena, "Review on widely-used MPPT Techniques for PV Applications", 2016 1st International Conference on Innovation and Challenges in Cyber Security (ICICCS 2016)

[2] Deepti Singh1, Ria Yadav2, Jyotsana3, "Perturb and Observe Method MATLAB Simulink and design of PV system using Buck Boost Converter ", International Journal of Science, Engineering and Technology Research (IJSETR), Volume 3, Issue 6, June 2014.

[3] Ahmed M. Atallah, Almoataz Y. Abdelaziz and Raihan S. Jumaah, "Implementation of Perturb and observe MPPT of PV system with direct control method using Buck and BuckBoost converter", Emerging Trends in Electrical, Electronics \& Instrumentation Engineering: An international Journal (EEIEJ), Vol. 1, No. 1, February 2014.

[4] Dalila Beriber, Abdelaziz Talha, "MPPT techniques for PV system", 4th International conference on power engineering energy and electrical drives, Istanbul, Turkey, Powereng, 13-17 May 2013

[5] Said Oucheriah and Liping Guo, "PWM-Based Adaptive Sliding-Mode Control for Boost DC-DC Converters", IEEE TRANSACTIONS ON INDUSTRIAL ELECTRONICS, VOL. 60, NO. 8, AUGUST 2013.

[6] Rahul Rawat and S. S. Chandel*[a], "Review of Maximum-Power-Point Tracking Techniques forSolar-Photovoltaic Systems", 2013 Wiley-VCH Verlag GmbH\&Co. KGaA, Weinheim.

[7] Tiong Meng Chung*, Hamdan Daniyal, Mohd Herwan Sulaiman, Mohd Shafie Bakar, "Comparative study of $\mathrm{P} \& \mathrm{O}$ and modified Incremental conductance algorithm in solar maximum power point tracking", 4th IET Clean Energy and Technology Conference, Kulala, Lumper, Malaysia, 2016.

[8] Hafsa Abouadane*,Abderrahim Fakkar, Youssef Elkouari, David Ouoba, "Performance of a new MPPT method for photovoltaic systems under dynamic solar irradiation profile ", 9th International Conference on Applied Energy, ICAE2017, 21-24 August 2017, Cardiff, UK.

[9] Omveer Singh, Shailesh Kumar Gupta, Haque, Ahteshamul, "A Review on Recent Maximum Power Point Tracking (MPPT) Scheme for solar photovoltaic System”, Energy Technology \& Policy, 2014.

[10] Moacyr Aureliano Gomes de Brito, Luigi Galotto, Jr. Leonardo Poltronieri Sampaio, Guilherme de Azevedo e Melo, and Carlos Albert Canesin, "Evalution of the Main MPPT Techniques for Photovoltaic Application", IEEE Transaction on Industrial Electronics, VOL. 60. NO. 3,pp 1156-1167, March 2013. 